\title{
Rare case of intra-oral palatal (soft palate) fibro-lipoma
}

\author{
Manit Mandal ${ }^{1}$, Ajay Panchal ${ }^{1}$, Rakesh Kumar ${ }^{1}$, Parth Kapadia ${ }^{1}$, and Neel Parmar ${ }^{1}$ \\ ${ }^{1}$ SMIMER
}

January 14, 2021

\begin{abstract}
Background: Case study of 30 years male having suspending mass found over upper surface of soft palate hanging in nasopharynx. Methods: After evaluation, patient underwent combined approach (Trans-oral + Endoscopic) excision. Results: Histopathological examination concluded possibility of intra-oral lipoma. Conclusion: Palatal mass (lipoma) requires surgical excision post complete evaluation.
\end{abstract}

\section{Hosted file}

Manuscript.pdf available at https://authorea.com/users/389413/articles/504023-rare-case-ofintra-oral-palatal-soft-palate-fibro-lipoma

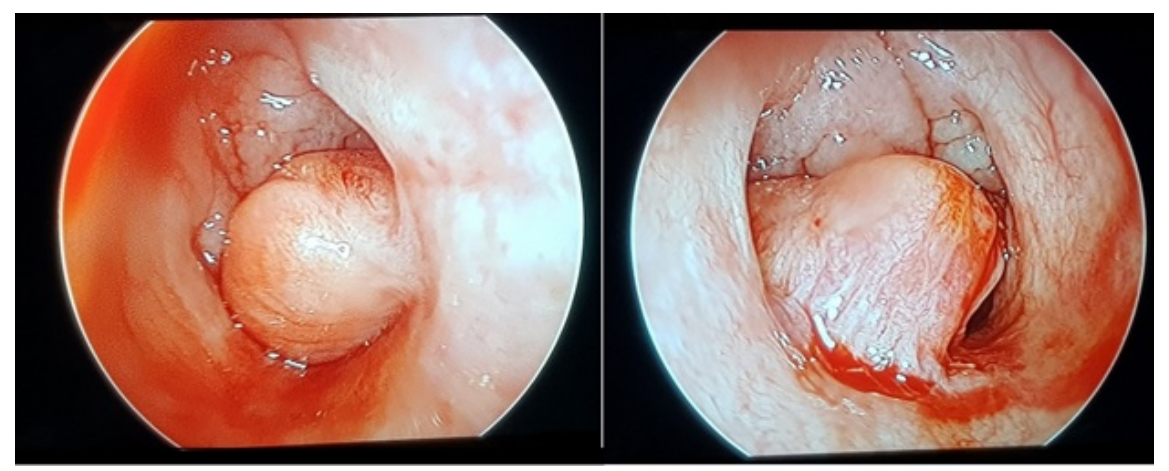




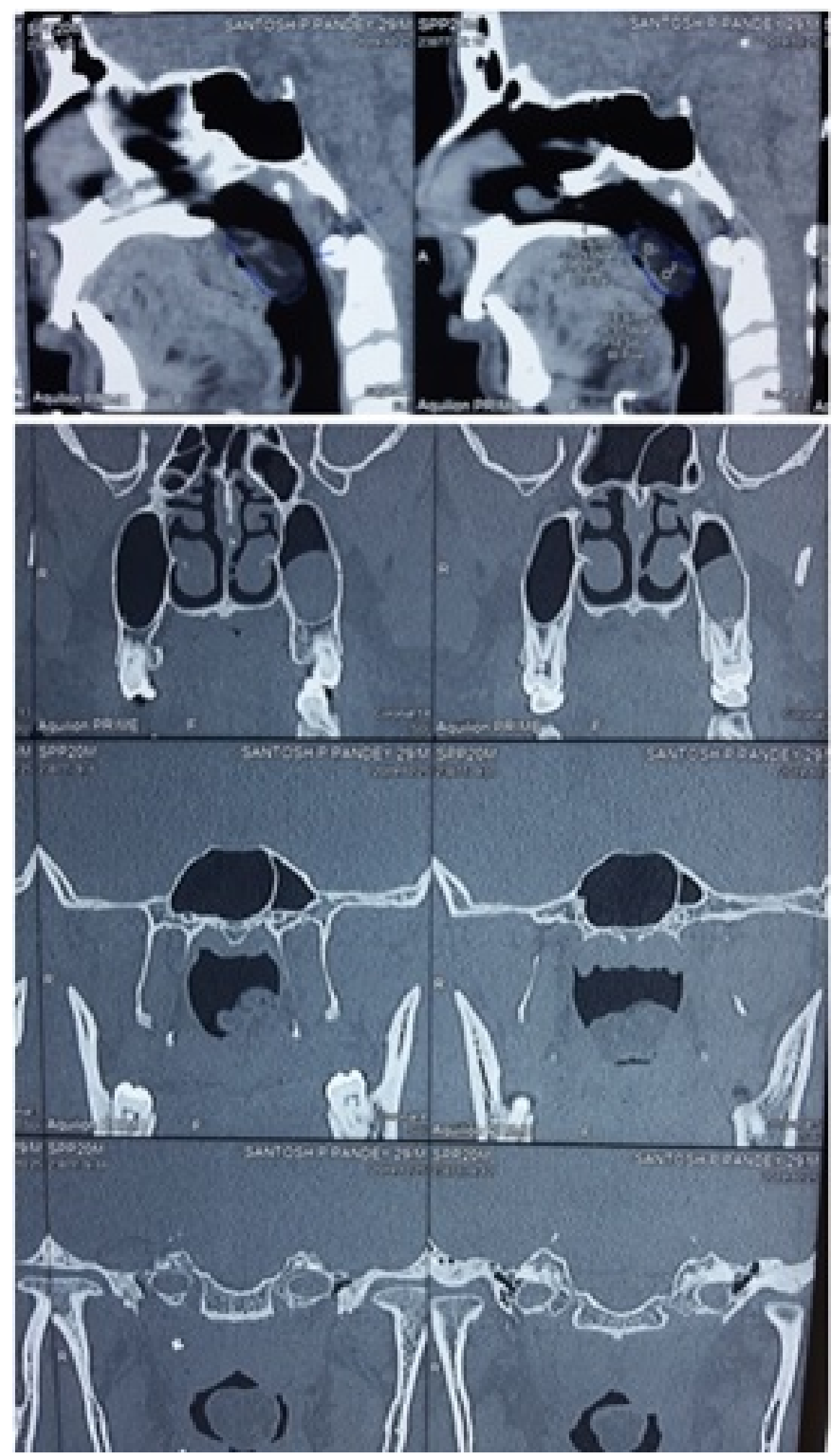




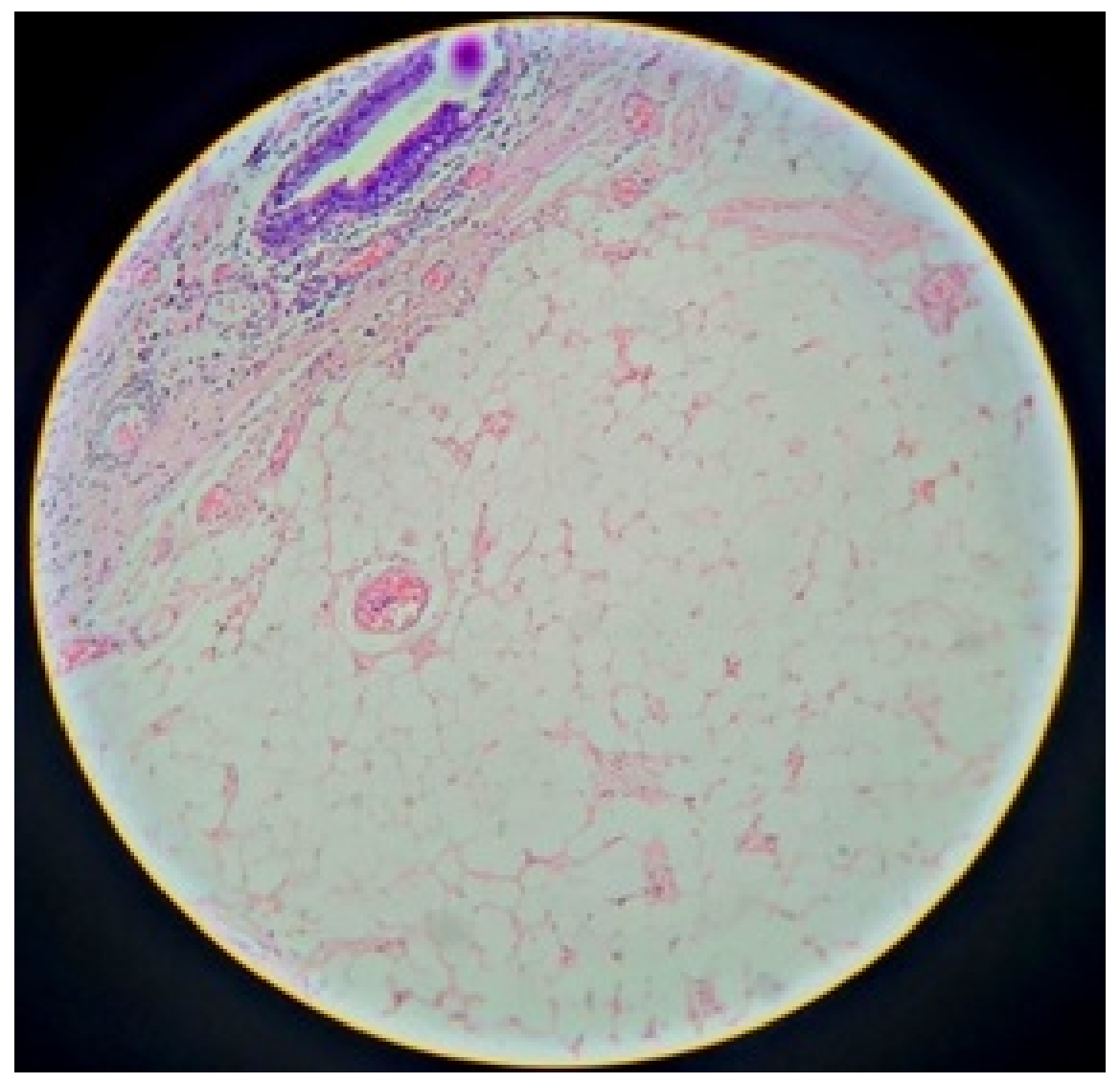

